\title{
Dehydroepiandrosterone Supplementation May Benefit Women with Asthma Who Have Low Androgen Levels: A Pilot Study
}

\author{
Nadzeya Marozkina · Joe Zein · Mark D. DeBoer · Laurie Logan • \\ Laura Veri · Kristie Ross · Benjamin Gaston
}

Received: September 3, 2019 / Published online: October 21, 2019

(C) The Author(s) 2019

\begin{abstract}
Introduction: Among individuals with severe asthma, $\mathrm{FEV}_{1}$ is low in individuals with low dehydroepiandrosterone (DHEA) sulfate (DHEAS) levels. In the Severe Asthma Research Program (SARP), no women with DHEAS $>200 \mu \mathrm{g} / \mathrm{dL}$ had an $\mathrm{FEV}_{1}<60 \%$ predicted. DHEA has benefited patients with COPD and pulmonary hypertension in small trials. Therefore, we hypothesized that DHEA supplementation may improve $\mathrm{FEV}_{1}$ in asthmatic women with low DHEAS.

Methods: Premenopausal, nonsmoking, otherwise healthy women, $18-50$ years old, with mild or moderate asthma and baseline $\mathrm{FEV}_{1}>60 \%$ predicted received $100 \mathrm{mg}$ DHEA orally every $12 \mathrm{~h}$ for 2 weeks. Spirometry and DHEAS were measured at the initial visit and 2 weeks later,
\end{abstract}

Enhanced Digital Features To view enhanced digital features for this article go to https://doi.org/10.6084/ m9.figshare.9939215.

N. Marozkina $\cdot$ J. Zein $\cdot$ K. Ross $\cdot$ B. Gaston ( $₫)$ Case Western Reserve University, Cleveland, $\mathrm{OH}$, USA

e-mail: begaston@iu.edu

M. D. DeBoer

University of Virginia, Charlottesville, VA, USA

L. Logan · L. Veri · K. Ross · B. Gaston

Rainbow Babies and Children's Hospital, Cleveland, $\mathrm{OH}$, USA after completion of DHEA treatment. Based on our previous work, the primary outcome variable for this pilot study was post-albuterol spirometry in the low-DHEAS group. Subjects also continued their other routine asthma management.

Results: Serum DHEAS increased with DHEA treatment in women with starting DHEAS $<200 \mu \mathrm{g} / \mathrm{dL}$ : this increase was from $71 \pm 23$ to $725 \pm 295 \mu \mathrm{g} / \mathrm{dL} \quad(n=10 ; \quad p=0.0001)$. The increase in the high-DHEAS group was smaller. Post-albuterol $\mathrm{FEV}_{1}$ increased by $51 \mathrm{~mL}$, from $3.026 \pm 0.5$ to $3.077 \pm 0.49 \mathrm{~L}(n=10 ; p=0.034$ by paired $t$ test, significant after Bonferroni), in women with low DHEAS. In the high-DHEAS group (baseline DHEAS $\geq 200 \mu \mathrm{g} / \mathrm{dl}$ ), post-albuterol $\mathrm{FEV}_{1}$ did not change significantly $(n=3$, $p=\mathrm{NS}$ ). Three subjects were excluded: one had comorbid COPD, one could not perform spirometry, and one did not take the DHEA. There were no adverse effects of DHEA treatment in this trial.

Conclusions: Endocrine treatments (corticosteroids) are a mainstay of anti-inflammatory management for moderate and severe asthma. Their use has improved asthma outcomes. Androgens also reduce airway inflammation and promote airway smooth muscle relaxation, but are rarely used clinically for asthma treatment. Our results suggest that the over-thecounter steroid DHEA may improve lung function in asthma outcomes among women with DHEAS $<200 \mathrm{ug} / \mathrm{dL}$. 
Keywords: Asthma; Dehydroepiandrosterone (DHEA); Lung function

\section{Key Summary Points}

Endocrine treatments (corticosteroids) are a mainstay of anti-inflammatory management for moderate and severe asthma.

Their use has improved asthma outcomes.

Androgens also reduce airway inflammation and promote airway smooth muscle relaxation, but are rarely used clinically.

Our results suggest that the over-thecounter steroid DHEA may also improve lung function in asthma outcomes among women with DHEAS $<200 \mathrm{ug} / \mathrm{dL}$.

\section{INTRODUCTION}

\section{Background and Significance Regarding Androgens for Patients with Asthma Who Have Low Circulating Androgen Levels}

In the United States, asthma affects over $8 \%$ of the population, leading to annual healthcare expenditures in excess of $\$ 20$ billion [1-5]. In severe asthma, chronic symptoms and exacerbation-prone disease persist despite the use of corticosteroids and other interventions in established management protocols [6-9]. Severe asthma accounts for the majority of the morbidity, mortality, and healthcare expenditures associated with asthma [7-9]. In the Severe Asthma Research Program (SARP), we investigated the distinct pathophysiological features of asthma in general, and severe asthma in particular [6, 7, 9-13]. In the SARP, we used the asthma and severe asthma definitions in the American Thoracic Society/European Respiratory Society consensus guidelines [9].

Asthma prevalence increases with age in women relative to men $[3,12]$. A particular focus of our SARP investigation has been to understand the relationship between asthma severity and sex hormones. Before puberty, the majority of patients with asthma are boys, while the majority of late adolescents and adults with asthma are women [12-14]. We measured circulating sex steroid levels and sex hormonebinding globulin (SHBG) in SARP subjects; specific hormones measured were estradiol, testosterone, progesterone, and dehydroepiandrosterone sulfate (DHEAS) [15]. Note that DHEAS is endogenously sulfated DHEA, and accounts for the majority of circulating DHEA. DHEA is synthesized from cholesterol via the enzymes cholesterol side-chain cleavage enzyme (CYP11A1; P450scc) and 17 $\alpha$-hydroxylase/17,20-lyase (CYP17A1), with pregnenolone and $17 \alpha$-hydroxypregnenolone as intermediates [16]. It functions as a metabolic intermediate in the biosynthesis of the androgen and estrogen sex steroids both in the gonads and in various other tissues. Metabolites of DHEA include DHEA-S, $7 \alpha$-hydroxy-DHEA, $7 \beta$-hydroxy-DHEA, 7-keto-DHEA, $7 \alpha$-hydroxyepiandrosterone, and $7 \beta$-hydroxyepiandrosterone, as well as androstenediol and androstenedione [17].

We found that post-albuterol $\mathrm{FEV}_{1}$ was strongly associated with low DHEA levels [15] and that DHEAS levels were twice as high in non-severe as in severe asthma. We also found that women with severe asthma had low levels of DHEAS compared with women with nonsevere asthma (58.1 vs $131.5 \mu \mathrm{g} / \mathrm{dL}, p<0.001)$. Strikingly, no women in our initial (SARP 1 and 2) cohort with DHEAS $>200 \mu \mathrm{g} / \mathrm{dL}$ had a forced expiratory volume at $1 \mathrm{~s}\left(\mathrm{FEV}_{1}\right.$, the standard marker for asthmatic airflow obstruction) $<60 \%$ predicted. To our knowledge, no other marker in humans is associated with such complete protection from low lung function. These data led us to hypothesize that DHEA supplementation in asthma subjects with low DHEA levels could improve lung function.

Of note, asthmatic men with low total testosterone levels had lower lung function than asthmatic men with normal testosterone levels-consistent with studies in non-asthmatic populations [18, 19] - and total testosterone values in men with severe asthma were lower than those in men with non-severe 
asthma. These data also suggest a protective effect of androgens on lung function. Further, DHEAS levels were strongly associated with lung function in male children [15]. For the majority of women and younger boys, adrenalderived DHEAS is the predominant androgen: the effect of testosterone is smaller. Taken together, these data suggest that androgens might improve lung function in asthma patients with low androgen levels. We have focused on DHEAS in women because DHEA supplementation is relatively safe and simpleit is an over-the-counter nutritional supplement used for inflammatory conditions [20-29]while testosterone administration involves injection of a controlled substance. Note also that glucocorticoid therapy can suppress endogenous DHEA production [30, 31]. Glucocorticoids are, as a class, steroid hormone derivatives that are beneficial preventively and therapeutically in both chronic and acute asthmatic airway inflammation [8, 9]. Patients with severe asthma tend to be glucocorticoidrefractory, even when treated with high doses $[9,10,32]$. It can be appropriately argued that low lung function associated with low DHEAS levels in our SARP data and related studies $[30,31]$ may reflect higher corticosteroid dosing used for these refractory patients with low lung function: that is, that low DHEAS might not be causally related to low lung function.

To begin to address whether low lung function is a cause or effect, we performed a pilot study, supplementing low DHEAS women with DHEA to determine whether increasing DHEAS levels by supplementation increased post-albuterol FEV .

DHEA has benefited patients with COPD $[28,33]$ and pulmonary hypertension $[28,34]$ in small trials, as well as animal models [35, 36]. Therefore, we hypothesize that DHEA treatment may also improve asthma outcomes.

\section{METHODS}

\section{Subjects and Approval}

We recruited premenopausal, nonsmoking, otherwise healthy women $18-50$ years of age with non-severe asthma and a baseline $\mathrm{FEV}_{1}>$ $60 \%$ predicted. They were recruited by public advertisement and from pulmonary clinics in Cleveland. All subjects who made inquiry regarding the study were screened and, if they met the criteria, were enrolled, with one exception: one woman declined to participate for family reasons. Inclusion and exclusion criteria were identical to those in the SARP for non-severe asthma, as we have published [37], except as noted in Table 1. Because of the slow turnaround in DHEAS levels, we treated all eligible women, but our target was women with low baseline DHEAS levels. Once we had the initial DHEAS levels, we stratified by level, above and below $200 \mathrm{ug} / \mathrm{dL}$. The study met ethics compliance and received institutional review board approval on 1 November 2016, UHCMC IRB number: 09-16-30. It was not entered into ClinicalTrials.gov because the protocol was approved and initiated in 2016, before the National Institutes of Health (NIH) clinical trials policy was posted or went into effect (18 January 2017), and it was not an NIHfunded clinical trial.

\section{Protocol}

At 8:00 a.m., after withholding medication for $12 \mathrm{~h}$, women underwent a urine pregnancy test as well as a history and physical exam. Those who were not pregnant and were not experiencing asthma exacerbation proceeded with the study. Baseline spirometry, maximum bronchodilator testing, and phlebotomy were performed at the initial visit and 2 weeks later, after the completion of DHEA treatment, according to SARP protocols $[7,37]$. Three milliliters of blood were drawn and sent to measure baseline DHEAS and other sex steroid levels (all assays required a total of $400 \mu \mathrm{L}$ serum in the SARP). All serum was bar-coded in Dr. Marozkina's lab and stored at $-80^{\circ} \mathrm{C}$ until assayed.

Subjects received $100 \mathrm{mg}$ DHEA orally every $12 \mathrm{~h}$ for 2 weeks, and they also continued their routine asthma management. Patients were given 28 pills by the research pharmacist. Those with non-allergic comorbidities were excluded $[7,8]$. The primary outcome variable was post- 
Table 1 Inclusion and exclusion criteria

\begin{tabular}{ll}
\hline Inclusion & Exclusion \\
\hline Female, 18-50 years old & Pregnant \\
$\begin{array}{l}\text { Asthma, stable and managed by an asthma } \\
\text { specialist [9] }\end{array}$ & Using hormonal contraception, pregnant \\
& Exclusion criteria for SARP [37], including both major comorbidities \\
& and smoking \\
& Endocrinopathy such as diabetes or PCOS (polycystic ovarian syndrom) \\
& Using androgens for any reason \\
& Postmenopausal \\
& Active asthma exacerbation \\
& FEV $<60 \%$ \\
\hline
\end{tabular}

albuterol $\mathrm{FEV}_{1}$; the secondary outcome variables were circulating DHEAS levels and pre-albuterol spirometry values.

\section{DHEA Preparation}

DHEA $100 \mathrm{mg}$ capsules were obtained from General Nutrition Corporation (GNC; Pittsburgh, PA 15222) and distributed by the research pharmacy.

\section{Statistical Analysis}

The primary outcome variable was change in post-bronchodilator $\mathrm{FEV}_{1}$. We used the paired Student $t$ test, Bonferroni test, and one-way analysis of variance (ANOVA) on ranks to analyze the data.

\section{RESULTS}

In this pilot study, 16 premenopausal women, 18-50 years of age, with non-severe asthma were studied. Three women were excluded from study: one who could not perform reproducible spirometry, one who had COPD, and one noncompliant (no changes in pre-post DHEAS levels). Those with low DHEAS $(<200 \mathrm{ug} / \mathrm{dL})$ and baseline $\mathrm{FEV}_{1}<80 \%$ predicted (baseline obstruction) who met the inclusion criteria (Table 1) had been identified in the screening visit. These exclusions included smoking and any major comorbidity.

Serum DHEAS increased after DHEA treatment from $71 \pm 23$ to $725 \pm 295 \mu \mathrm{g} / \mathrm{dL}(n=10$; $p=0.0001$ ) in the low-DHEAS group (baseline DHEAS $<200 \mu \mathrm{g} / \mathrm{dl}$ ). However, in the highDHEAS group (baseline DHEAS $\geq 200 \mu \mathrm{g} / \mathrm{dl}$ ), the increase in serum DHEAS after DHEA treatment did not reach statistical significance, increasing from $214 \pm 18$ to $458 \pm 170 \mu \mathrm{g} / \mathrm{dL}$ $(n=3 ; p=\mathrm{NS})$.

We compared the change in post-albuterol $\mathrm{FEV}_{1}$ (primary outcome) and change in DHEAS in women whose starting DHEAS was $<200 \mu \mathrm{g} /$ dL. Post-albuterol $\mathrm{FEV}_{1}$ increased by $51 \mathrm{~mL}$, from $3.026 \pm 0.5$ to $3.077 \pm 0.49 \mathrm{~L} \quad(n=10$; $p=0.034$ by paired $t$ test, significant after Bonferroni test), in women with low DHEAS (Table 2). However, in the high-DHEAS group (baseline DHEAS $\geq 200 \mu \mathrm{g} / \mathrm{dl}$ ), corrective postalbuterol $\mathrm{FEV}_{1}$ did not change significantly $(n=3, p=\mathrm{NS})$.

We analyzed other respiratory parameters obtained by spirometry, such as pre- and postalbuterol changes in forced vital capacity (FVC), FEV/FVC \%, FEV 75/25 following DHEA treatment by one-way ANOVA on ranks, and paired 
Table 2 Spirometry value changes after DHEA treatment

\begin{tabular}{lllll}
\hline Spirometry & \multicolumn{2}{l}{ Low-DHEAS group } & \multirow{2}{*}{$\boldsymbol{N}$} & \multirow{2}{*}{$\boldsymbol{P}$} \\
\cline { 2 - 5 } & No treatment & + DHEA treatment & & \\
\hline${\text { Baseline } \mathrm{FEV}_{1} \text { change }}_{\text {Post-albuterol FEV }}$ change & $2.952 \pm 0.468$ & $2.986 \pm 0.505$ & 7 & 0.276 \\
\hline
\end{tabular}

Student $t$ test. In all these parameters, changes did not reach statistical significance.

There were no adverse effects of DHEA treatment reported in any of the patients participating in this trial.

\section{DISCUSSION}

In our two SARP study cohorts combined (SARP 1 and 2; and SARP 3), women with a DHEAS level $>200 \mu \mathrm{g} / \mathrm{dL}$ did not have severely compromised $\mathrm{FEV}_{1}$. Indeed, DHEAS was previously shown to be associated with protection against inflammation in general, and asthmatic airway inflammation in particular $[15,19-21,28,29$, $38,39]$. However, the heterogeneity of determinants of androgen levels makes it difficult to ascertain both efficacy and mechanism. In this pilot study, our low-DHEAS adult asthmatic women with airflow obstruction received a 2-week course of DHEA, and the primary outcome variable was improvement in $\mathrm{FEV}_{1}$. We may also have a better understanding of the potential protective effects of androgens that could help explain the tendency of asthma prevalence to increase with age in women relative to men. Cortisol-like compounds have been effective agents for the management of many patients with asthma, but other hormones have not been systemically studied. Here, we have studied the use of a safe, easily available, and inexpensive androgen to treat asthma. This study thus has a high potential for return on investment, improving the health of many patients with severe asthma and reducing asthma healthcare costs.

\section{Potential Mechanisms by which Androgens May Benefit Patients with Asthma}

The potential protective effects of DHEAS likely involve effects both on airway smooth muscle and on airway inflammation. Indeed, there is evidence to support cross-talk between DHEAS anti-inflammatory effects and airway smooth muscle relaxation $[38,40]$. DHEAS inhibits human airway smooth muscle and fibroblast proliferation [39, 41], may benefit airway epithelial-to-mesenchymal transition [42], and is itself a bronchodilator [43]. It also benefits pulmonary vascular smooth muscle tone, and is used as treatment for human pulmonary arterial hypertension [28]. Note that testosterone also promotes airway smooth muscle relaxation [41].

DHEAS also has anti-inflammatory effects in murine (dust mitel) asthma models, decreasing airway interleukin (IL) 4, IL5, and interferon gamma [44, 45], and reducing airway eosinophilia in an ovalbumin model [38]. Note that testosterone was also recently shown to be associated with decreasing type 2 innate lymphoid cell-mediated inflammation in a murine asthma model [46]. DHEAS is also associated with lower systemic IL6 levels, proposed to be involved in its neuroprotective effects in human stroke [29]. DHEA exerts anti-inflammatory effects observed in a variety of nonasthmatic human conditions [20-23, 47, 48], in many of which it is used as a nutritional supplement therapy.

This pilot study will be the basis for larger double-blind randomized controlled trials. It was shown previously [21] that nebulized DHEA improves asthma symptoms (reflected by Asthma Control Questionnaire) in moderate-to- 
severe asthma in a randomized, double-blind, placebo-controlled study. This pilot will be used to power a larger study of oral DHEA supplementation in the future larger double-blind randomized controlled trial.

\section{CONCLUSIONS}

Corticosteroids related to cortisol are a mainstay of anti-inflammatory treatment for moderate and severe asthma. Their use has improved asthma outcomes. However, androgens also reduce airway inflammation and promote airway smooth muscle relaxation. Our preliminary data suggest that the over-the-counter steroid DHEA also improves lung function in asthma outcomes among women with DHEAS $<200$ $\mathrm{ug} / \mathrm{dL}$. Low-dose over-the-counter androgen supplementation may benefit certain women with asthma, particularly those with low serum DHEAS levels, and is safe in given doses. Additional studies will be worthwhile.

\section{ACKNOWLEDGMENTS}

Funding. This study was funded by the Children's Lung Foundation and (U10HL109 250 [SARP]). The Rapid Service Fee was funded by the authors.

Authorship. All named authors meet the International Committee of Medical Journal Editors (ICMJE) criteria for authorship for this article, take responsibility for the integrity of the work as a whole, and have given their approval for this version to be published.

Disclosures. Nadzeya Marozkina, Joe Zein, Mark D. DeBoer, Laurie Logan, Laura Veri, Kristie Ross, and Benjamin Gaston have nothing to disclose.

Compliance with Ethics Guidelines. The study met ethics compliance and received institutional review board approval on 1 November 2016, UHCMC IRB number: 09-1630. It was not entered into ClinicalTrials.gov because the protocol was approved and initiated in 2016, before the NIH clinical trials policy was posted or went into effect (18 January 2017), and it was not an NIH-funded clinical trial. Informed consent to participate was given by all participants.

Open Access. This article is distributed under the terms of the Creative Commons AttributionNonCommercial 4.0 International License (http://creativecommons.org/licenses/by-nc/4. $0 /$ ), which permits any non-commercial use, distribution, and reproduction in any medium, provided you give appropriate credit to the original author(s) and the source, provide a link to the Creative Commons license, and indicate if changes were made.

\section{REFERENCES}

1. Centers for Disease Control National Health Interview Survey, 2012. Source: summary Health Statistics for U.S. Adults: National Health Interview Survey. 2012. http://www.cdc.gov/nchs/fastats/ asthma.htm. Accessed 15 Oct 2019.

2. Centers for Disease Control National Health Interview Survey, 2010, Source: National Ambulatory Medical Care Survey. 2010:Summary Tables, table 13. http://www.cdc.gov/nchs/fastats/asthma. htm.

3. Centers for Disease Control and Prevention, Vital Signs (monthly statistical report). 2011. https:// www.cdc.gov/vitalsigns/pdf/2011-05-vitalsigns.pdf. Accessed 15 Oct 2019.

4. Slejko JF, Ghushchyan VH, Sucher B, Globe DR, Lin SL, Globe G, et al. Asthma control in the United States, 2008-2010: indicators of poor asthma control. J Allergy Clin Immunol. 2014;133(6):1579-87.

5. Morbidity and Mortality Report. National Center for Health Statistics (NCHS), U.S. CDC. 2003.

6. Marozkina NV, Wang XQ, Stsiapura V, Fitzpatrick A, Carraro S, Hawkins GA, et al. Phenotype of asthmatics with increased airway S-nitrosoglutathione reductase activity. Eur Respir J. 2015;45(1):87-97.

7. Moore WC, Bleecker ER, Curran-Everett D, Erzurum SC, Ameredes BT, Bacharier L, et al. Characterization of the severe asthma phenotype by the National Heart, Lung, and Blood Institute's Severe 
Asthma Research Program. J Allergy Clin Immunol. 2007;119(2):405-13.

8. National Heart Lung and Blood Institute. Guidelines for the diagnosis and treatment of asthma (EPR3). 2007. http://www.nhlbi.nih.gov/healthpro/guidelines/current/asthma-guidelines. Accessed 15 Oct 2019.

9. Chung KF, Wenzel SE, Brozek JL, Bush A, Castro M, Sterk PJ, et al. International ERS/ATS guidelines on definition, evaluation and treatment of severe asthma. Eur Respir J. 2014;43(2):343-73.

10. Denlinger LC, Phillips BR, Ramratnam S, Ross K, Bhakta NR, Cardet JC, et al. Inflammatory and comorbid features of patients with severe asthma and frequent exacerbations. Am J Respir Crit Care Med. 2017;195(3):302-13.

11. Greenwald R, Fitzpatrick AM, Gaston B, Marozkina NV, Erzurum S, Teague WG. Breath formate is a marker of airway S-nitrosothiol depletion in severe asthma. PLoS One. 2010;5(7):e11919.

12. Zein JG, Udeh BL, Teague WG, Koroukian SM, Schlitz NK, Bleecker ER, et al. Impact of age and sex on outcomes and hospital cost of acute asthma in the United States, 2011-2012. PLoS One. 2016;11(6):e0157301.

13. Becklake MR, Kauffmann F. Gender differences in airway behaviour over the human life span. Thorax. 1999;54(12):1119-38.

14. Zein JG, Erzurum SC. Asthma is different in women. Curr Allergy Asthma Rep. 2015;15(6):28.

15. DeBoer MD, Phillips BR, Mauger DT, Zein J, Erzurum SC, Fitzpatrick AM, et al. Effects of endogenous sex hormones on lung function and symptom control in adolescents with asthma. BMC Pulm Med. 2018;18(1):58.

16. Rainey WE, Nakamura Y. Regulation of the adrenal androgen biosynthesis. J Steroid Biochem Mol Biol. 2008;108(3-5):281-6. https://doi.org/10.1016/j. jsbmb.2007.09.015 (PMC 2699571. PMID 17945481).

17. Mo Q, Lu SF, Simon NG. Dehydroepiandrosterone and its metabolites: differential effects on androgen receptor trafficking and transcriptional activity. J Steroid Biochem Mol Biol. 2006;99(1):50-8. https://doi.org/10.1016/j.jsbmb.2005.11.011. (PMID 16524719).

18. Swartz MA, Tschumperlin DJ, Kamm RD, Drazen JM. Mechanical stress is communicated between different cell types to elicit matrix remodeling. Proc Natl Acad Sci USA. 2001;98(11):6180-5.
19. Mohan SS, Knuiman MW, Divitini ML, James AL, Musk AW, Handelsman DJ, et al. Higher serum testosterone and dihydrotestosterone, but not oestradiol, are independently associated with favourable indices of lung function in communitydwelling men. Clin Endocrinol. 2015;83(2):268-76.

20. Traish AM, Kang HP, Saad F, Guay AT. Dehydroepiandrosterone (DHEA) — a precursor steroid or an active hormone in human physiology. J Sex Med. 2011;8(11):2960-82 (quiz 83).

21. Wenzel SE, Robinson CB, Leonard JM, Panettieri RA Jr. Nebulized dehydroepiandrosterone-3-sulfate improves asthma control in the moderate-to-severe asthma results of a 6-week, randomized, doubleblind, placebo-controlled study. Allergy Asthma Proc. 2010;31(6):461-71.

22. Taylor MK, Padilla GA, Stanfill KE, Markham AE, Khosravi JY, Ward MD, et al. Effects of dehydroepiandrosterone supplementation during stressful military training: a randomized, controlled, double-blind field study. Stress (Amsterdam, Netherlands). 2012;15(1):85-96.

23. Weiss EP, Villareal DT, Fontana L, Han DH, Holloszy JO. Dehydroepiandrosterone (DHEA) replacement decreases insulin resistance and lowers inflammatory cytokines in aging humans. Aging. 2011;3(5):533-42.

24. Stanczyk FZ, Slater CC, Ramos DE, Azen C, Cherala G, Hakala C, et al. Pharmacokinetics of dehydroepiandrosterone and its metabolites after longterm oral dehydroepiandrosterone treatment in postmenopausal women. Menopause (New York, NY). 2009;16(2):272-8.

25. Acacio BD, Stanczyk FZ, Mullin P, Saadat P, Jafarian N, Sokol RZ. Pharmacokinetics of dehydroepiandrosterone and its metabolites after longterm daily oral administration to healthy young men. Fertil Steril. 2004;81(3):595-604.

26. Arlt W, Justl HG, Callies F, Reincke M, Hubler D, Oettel $\mathrm{M}$, et al. Oral dehydroepiandrosterone for adrenal androgen replacement: pharmacokinetics and peripheral conversion to androgens and estrogens in young healthy females after dexamethasone suppression. J Clin Endocrinol Metab. 1998;83(6):1928-34.

27. Buster JE, Casson PR, Straughn AB, Dale D, Umstot ES, Chiamori $\mathrm{N}$, et al. Postmenopausal steroid replacement with micronized dehydroepiandrosterone: preliminary oral bioavailability and dose proportionality studies. Am J Obstet Gynecol. 1992;166(4):1163-8 (discussion 8-70).

28. La Dumas Roque E, Savineau JP, Metivier AC, Billes MA, Kraemer JP, Doutreleau $S$, et al. 
Dehydroepiandrosterone (DHEA) improves pulmonary hypertension in chronic obstructive pulmonary disease (COPD): a pilot study. Annales d'endocrinologie. 2012;73(1):20-5.

29. Hollig A, Thiel M, Stoffel-Wagner B, Coburn M, Clusmann H. Neuroprotective properties of dehydroepiandrosterone-sulfate and its relationship to interleukin 6 after aneurysmal subarachnoid hemorrhage: a prospective cohort study. Crit Care (London, England). 2015;19(1):231. (PMID 25993987).

30. Dorsey MJ, Cohen LE, Phipatanakul W, Denufrio D, Schneider LC. Assessment of adrenal suppression in children with asthma treated with inhaled corticosteroids: use of dehydroepiandrosterone sulfate as a screening test. Ann Allergy Asthma Immunol. 2006;97(2):182-6.

31. Reinke SN, Gallart-Ayala H, Gomez C, Checa A, Fauland A, Naz S, et al. Metabolomics analysis identifies different metabotypes of asthma severity. Eur Respir J. 2017;49(3). (PMID 28356371).

32. Phipatanakul W, Mauger DT, Sorkness RL, Gaffin JM, Holguin F, Woodruff PG, et al. Effects of age and disease severity on systemic corticosteroid responses in asthma. Am J Respir Crit Care Med. 2017;195(11):1439-48.

33. Zurfluh S, Nickler M, Ottiger M, Steuer C, Kutz A, Christ-Crain $\mathrm{M}$, et al. Association of adrenal hormone metabolites and mortality over a 6-year follow-up in COPD patients with acute exacerbation. Clin Chem Lab Med. 2018;56(4):669-80.

34. Dubuis E. DHEA treatment of pulmonary hypertension: new insights into a complex mechanism. Cardiovasc Res. 2007;74(3):337-8.

35. Zhang YT, Xue JJ, Wang Q, Cheng SY, Chen ZC, Li HY, et al. Dehydroepiandrosterone attenuates pulmonary artery and right ventricular remodeling in a rat model of pulmonary hypertension due to left heart failure. Life Sci. 2019;219:82-9.

36. Alzoubi A, Toba M, Abe K, O’Neill KD, Rocic P, Fagan KA, et al. Dehydroepiandrosterone restores right ventricular structure and function in rats with severe pulmonary arterial hypertension. Am J Physiol Heart Circ Physiol. 2013;304(12):H1708-18.

37. Teague WG, Phillips BR, Fahy JV, Wenzel SE, Fitzpatrick AM, Moore WC, et al. Baseline features of the severe asthma research program (SARP III) cohort: differences with age. J Allergy Clin Immunol Pract. 2018;6(2):545.e4-554.e4.
38. Liou CJ, Huang WC. Dehydroepiandrosterone suppresses eosinophil infiltration and airway hyperresponsiveness via modulation of chemokines and Th2 cytokines in ovalbumin-sensitized mice. J Clin Immunol. 2011;31(4):656-65.

39. Mendoza-Milla C, Valero Jimenez A, Rangel C, Lozano A, Morales V, Becerril C, et al. Dehydroepiandrosterone has strong antifibrotic effects and is decreased in idiopathic pulmonary fibrosis. Eur Respir J. 2013;42(5):1309-21.

40. Bosse Y. Endocrine regulation of airway contractility is overlooked. J Endocrinol. 2014;222(2):R61-73.

41. Kouloumenta V, Hatziefthimiou A, Paraskeva E, Gourgoulianis K, Molyvdas PA. Non-genomic effect of testosterone on airway smooth muscle. $\mathrm{Br} \mathrm{J}$ Pharmacol. 2006;149(8):1083-91.

42. Xu L, Xiang X, Ji X, Wang W, Luo M, Luo S, et al. Effects and mechanism of dehydroepiandrosterone on epithelial-mesenchymal transition in bronchial epithelial cells. Exp Lung Res. 2014;40(5):211-21.

43. Espinoza J, Montano LM, Perusquia M. Nongenomic bronchodilating action elicited by dehydroepiandrosterone (DHEA) in a guinea pig asthma model. J Steroid Biochem Mol Biol. 2013;138:174-82.

44. Yu CK, Liu YH, Chen CL. Dehydroepiandrosterone attenuates allergic airway inflammation in Dermatophagoides farinae-sensitized mice. J Microbiol Immunol Infect. 2002;35(3):199-202.

45. Yu CK, Yang BC, Lei HY, Chen YC, Liu YH, Chen $\mathrm{CC}$, et al. Attenuation of house dust mite Dermatophagoides farinae-induced airway allergic responses in mice by dehydroepiandrosterone is correlated with down-regulation of $\mathrm{TH} 2$ response. Clin Exp Allergy. 1999;29(3):414-22.

46. Cephus JY, Stier MT, Fuseini H, Yung JA, Toki S, Bloodworth $\mathrm{MH}$, et al. Testosterone attenuates group 2 innate lymphoid cell-mediated airway inflammation. Cell Rep. 2017;21(9):2487-99.

47. Simoncini T, Mannella P, Fornari L, Varone G, Caruso A, Genazzani AR. Dehydroepiandrosterone modulates endothelial nitric oxide synthesis via direct genomic and nongenomic mechanisms. Endocrinology. 2003;144(8):3449-55.

48. Hampl V, Bibova J, Povysilova V, Herget J. Dehydroepiandrosterone sulphate reduces chronic hypoxic pulmonary hypertension in rats. Eur Respir J. 2003;21(5):862-5. 